\title{
Quality Management Principles in the University-Industry Partnership
}

\author{
Eva-Nicoleta BURDUSEL \\ "Lucian Blaga" University of Sibiu, Romania \\ eva.burdusel@ulbsibiu.ro \\ Liviu BALAN \\ Continental Automotive Systems SRL Sibiu, Romania \\ liviu.balan@continental-corporation.com \\ Anca OPREAN \\ Continental Automotive Systems SRL Sibiu, Romania \\ anca.oprean@continental-corporation.com
}

\begin{abstract}
Purpose of the work

In the context of an intensified and successful cooperation between Continental Automotive Systems SRL and Lucian Blaga University of Sibiu, Romania, the most recent initiative is to undertake a research investigation meant to examine the collaboration between higher education and business and identify new means to increase the efficiency of their partnership taking into account the present challenges addressing both academia and industry, as well as facilitating the transition from the former to the latter in the context of the labour market demands.

Methodology

The study will provide an analysis of the public-private partnership based on a recent case study endorsed by a thorough theoretical framework. In this respect, an anonymous questionnaire was addressed to two target groups: employees and team/department leaders at Continental Automotive Systems SRL Sibiu.

Important findings

The results of the case study will provide relevant feedback about the ability of new employees to integrate on the labour market and make full use of the abilities and competencies developed and trained throughout their academic education. Since the present study is a follow up of previous research projects, the case study will now focus on "non-technical talents", therefore the target group of the questionnaire is represented by employees and team leaders from the following departments: translation services, human resources, purchasing, logistics, finance and controlling.

Conclusions that identify implications for future practice and/or policy and key "Take Home Messages"
\end{abstract}


The present paper highlights the relevance of each component of the knowledge triangleeducation, research, innovation - as a means to prevent and overcome crisis evinced as: unemployment in addition to graduates' inability to integrate or adapt to the requirements of business community, labour market mobility and financial instability, economic competitiveness.

Keywords: non-technical talents; knowledge triangle; academia-industry partnership

\section{SETTING THE CONTEXT}

"As the global knowledge economy grows, the need for greater synergies between education, science and business becomes even more urgent. Whether we work in an EU institution, a university, a research institute, a company, or a government agency, we have all a role to play in building a more competitive, sustainable and cohesive Europe." (Navracsics, 2015) In a very recent speech addressed on the occasion of the 2015 Science Business Horizon 2020 Conference, EU Commisssioner for Education, Culture, Youth and Sport, Tibor Navracsics reinforced the connection among the components of the knowledge triangle. Furthermore, the EU Commissioner emphasizes the commitment to strengthening partnerships between universities and the world of work and promoting culture as a catalyst for innovation, economic growth and new jobs, illustrated in a number of key speeches addressed mainly on the occasion of Conference opening ceremonies.

The present study, undertaken by a collaborative team representing both university and industry, aims to provide a recent, fair, well-documented and balanced perspective - the educators and employers alike - on the right mix of skills, attitudes and values - i.e. key and transversal competencies - for better employability and facilitating the transition from the curriculum-based learning institution to the task-oriented learning organization. In the work-based environment, core competencies evince the employee`s expertise in a specific area acquired throughout formal education, whereas transversal competencies, also referred to as " $21^{\text {st }}$ century skills", enable the employee to "successfully navigate the changing global landscape and ... to meet the challenges of technological advancement and intercultural communication." (Unesco, 2015)

Further to previous studies jointly developed by Lucian Blaga University of Sibiu and Continental Automotive Systems SRL Sibiu endorsing the successful collaboration between academic and business organizations, the paper aims to raise awareness - of scholars, practitioners and community - and enhance understanding of the vital necessity to empower graduates with "life skills" and transversal competencies hence to facilitate their employability and integration on the labor market. The connection and interaction of the triad - higher education institutions, business and community - has become a hallmark of the knowledge cycle paradigm, especially acute at a time of changing context: legislative, socio-cultural, economic and scientific.

Knowledge creation and dissemination are essential components of the learning organization in the knowledge-based society and economy. Now, more than ever, the mission of universities is to act as knowledge brokers and consider thoroughly the 
demands of all stakeholders. According to the European Commission 2012 Communication on Rethinking Education, "investment in education and training for skills development is essential to boost growth and competitiveness: skills determine Europe`s capacity to increase productivity. In the long term, skills can trigger innovation and growth, move production up the value chain, stimulate the concentration of higher level skills in the EU and shape the future labour market." (European Commission, 2012)

Summing up, the process of rethinking education is designed in a socio-economic context; thus adapting education to the needs of the workplace needs requires: delivering the right skills of employment in addition to new ways of teaching and learning

The goal of the present study is twofold: on the one hand, it will highlight the successful partnership between Lucian Blaga University of Sibiu and Continental Automotive Systems Sibiu as an example of best practice in university - industry collaboration given the interdependence of the higher education and economic sectors; on the other hand, it urges the reader to balance the study in humanities and sciences (Nussbaum, 2010).

The future of higher education is linked and even bound by economic crises or progress, especially in terms of funding, contribution to economic growth and community outreach; moreover, education has still untapped potential to shape and design the future. It is in this context that the present study will argue for the necessity of training "non-technical talents" supported by a case study.

\section{KNOWLEDGE CYCLE PARADIGM: UNIVERSITY - COMMUNITY - BUSINESS}

Nowadays, higher education institutions - notwithstanding the multiple challenges they have to cope with and successfully overcome, operating in an economic and legal context marked by unpredictability and subject to increasing internal and international competition - act as knowledge brokers in a new paradigm of learning and innovation. Universities not only create knowledge, they should also connect their research findings to business organizations, transfer technology advancement to society development and evince an active engagement in the life of their community. However, let us not consider universities as mere consultants to companies, instead a more sustainable approach points out to a shift from a "transactional" to a "transformational" intervention according to the EU Practical Guide Connecting Universities to Regional Growth. "In meeting major societal challenges, which have both a global and local dimension, universities and other higher education institutions have a key role to play in knowledge creation and its translation into innovative products and public and private services, a process that can engage the creative arts and social sciences as well as scientists and technologists." (Goddard, 2011)

As mentioned in the rationale of this study, the major goal is to call attention to the role of social sciences and humanities in both industrial and academic organizations - especially at a time when triggered by utilitarian, pragmatic, market-oriented considerations and the need to overcome and survive in the aftermath of the recent economic and financial crisis, whose effects are still with us - in addition to the acute need of reconciling the divide between soft and hard sciences. 
According to the 2011 Romanian Education Law, the major vision of the national education system is to promote "an education focused on values, creativity [...] fundamental knowledge as well as applied knowledge, competencies and skills in view of further use in society and profession" as well as undertaking the mission of training "by means of education, the mental infrastructure of Romanian society, in keeping with the new requirements entailed by Romania`s recent EU membership accompanied by globalization, as well as the sustainable creation of highly competitive national human resource, able to perform efficiently in the current and future society." (Monitorul Oficial, 2011) Professional and transversal competencies, in addition to the eight key competences for lifelong learning (European Parliament, 2006) enable graduates to evince an integrative approach to the assigned professional tasks, to communicate their ideas effectively, as well as their willingness and propensity to relate and perform properly in a team. Furthermore, the 2009 Leuven Communique (The Bologna Process 2020) highlighted the relevance of employability and the urgent need for intertwining education - research - innovation as main priorities for the second decade subsequent to the adoption of the Bologna Process.

Based on the knowledge cycle paradigm that brings to the forefront the interdependence of the three stakeholders: university - community - business, as well as Daniel Smihula`s theory that "technological revolutions are the main engine of economic development and hence long-term economic cycles are dependent on these waves of technological innovation." (Smihula, 2011) Nowadays, in the aftermath of the recent economic crisis with global and multiple consequences, key decision and policy makers should be aware that - despite ineluctable financial considerations or constraints alongside the pressure for economic growth in a society characterized by profitability and resource efficiency, as well as high performance and measurable impact in terms of academic output - the contribution of each academic discipline, area or researcher is essential for the development of society.

\section{CASE STUDY}

In the context of an intensified and successful cooperation between Continental Automotive Systems SRL and Lucian Blaga University of Sibiu, Romania, the authors of the present study have undertaken a new scientific project endorsed by a questionnaire addressed Continental employees. The aim of this anonymous survey is to analyze, based on a case study endorsed by a thorough theoretical framework, the cooperation between the higher education institution and the industrial organization, i.e. public-private partnership, from an employer's perspective in accordance with the requirements of the labour market. The results of the case study provide relevant feedback about the ability of new employees to integrate on the labour market and make full use of the abilities and competencies developed and trained throughout their academic education. Since the present paper follows up on previous research projects, the case study will now focus on "non-technical talents", therefore the target group of the questionnaire is represented by new entries to the company and university graduates, as well as team leaders from the following departments: translation services, human resources, purchasing, logistics, finance and controlling. 
Here are the results of the questionnaire addressed to new entries and former university graduates:

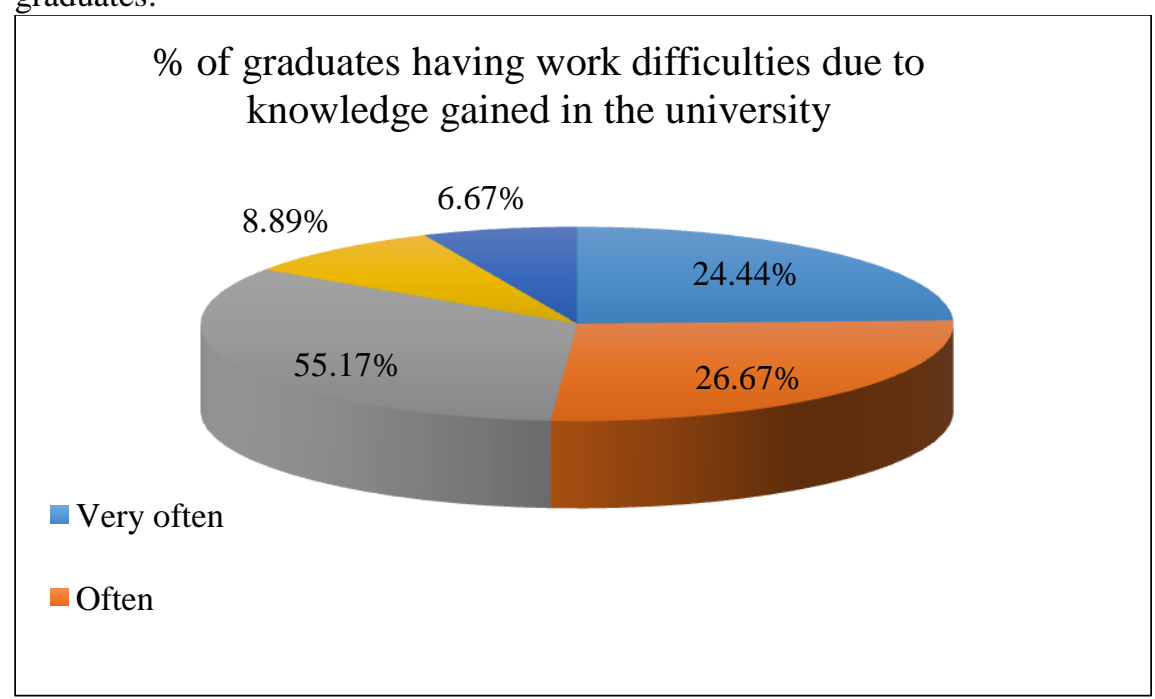

Figure 1: Percentage of graduates having work difficulties due to knowledge gained in the university

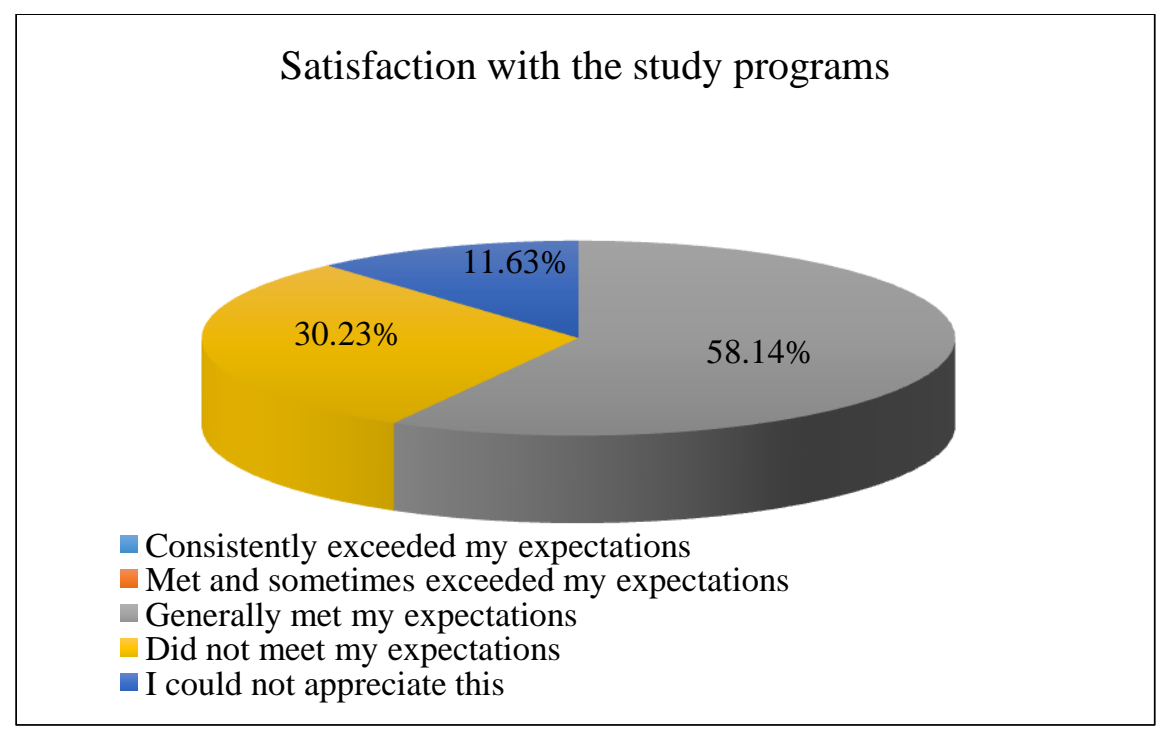

Figure 2: Satisfaction with the study programs 


\section{Desire for further university programs}

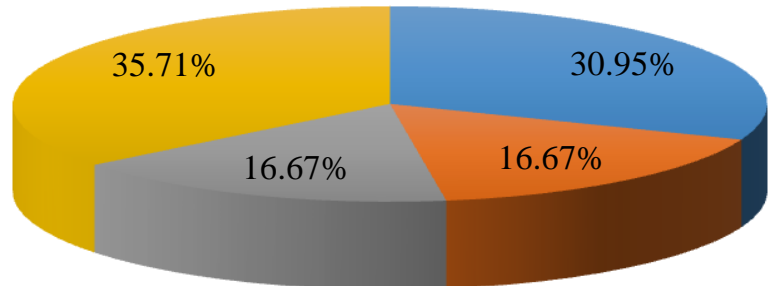

Yes,I would like to get more experienced within my field to improve my skills

Yes,I think a new diploma would be a bighelp for me

Figure 3: Desire for future university programs

Satisfaction toward assigned work activities

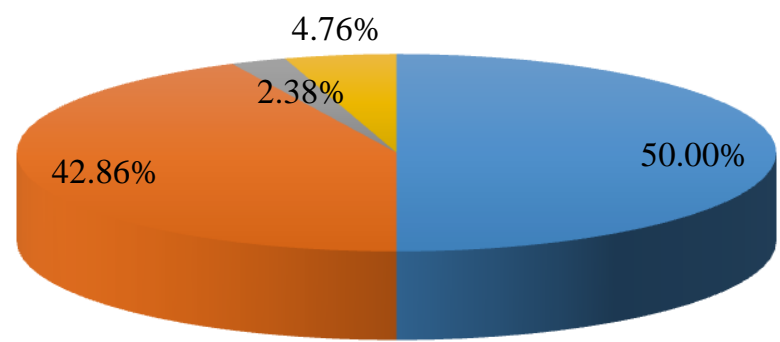

- So far,I like the tasks assigned to me

- I usually like my tasks, but not all the time

I don't like my tasks

My tasks are too easy,I would like to do something more complex

Figure 4: Satisfaction towards assigned work activities 
Education level of ULBS compared with other universities

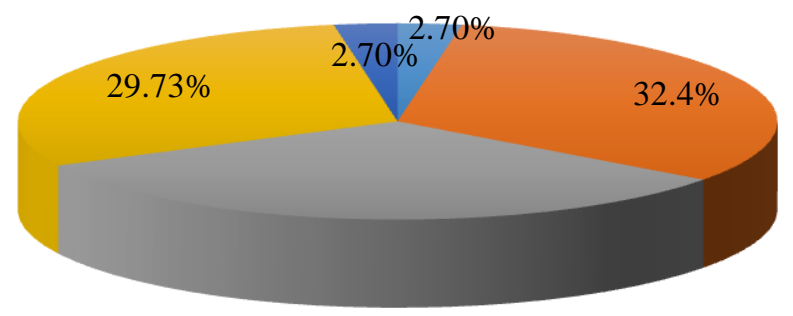

$\square$ Excellent $\quad$ Very good $\quad$ Good $\quad$ Fair $\square$ Poor

Figure 5: Education level of ULBS compared with other universities

Secondly, the questionnaire addressed to team and department leaders shows the following results:

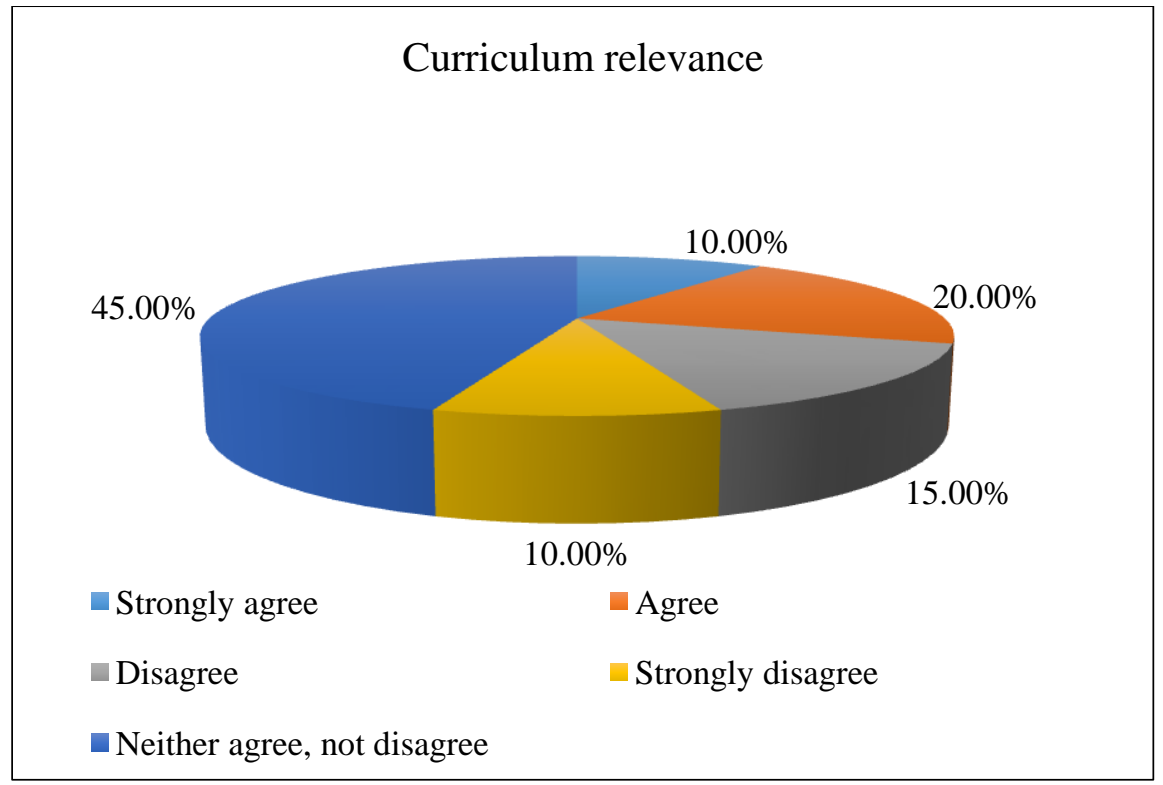


Figure 6: Curriculum relevance

Relevance of automotive/electronics courses

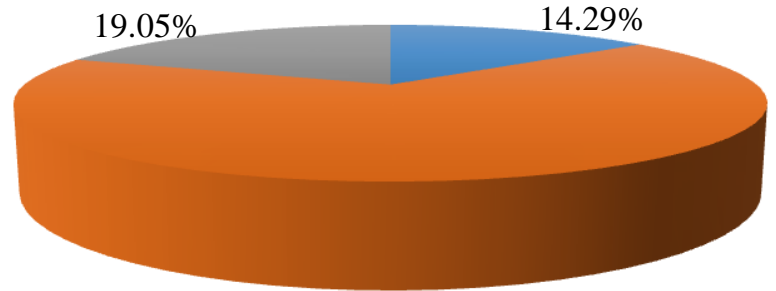

$66.67 \%$

To a grate extent $\quad$ To o lesser degree $\quad$ Not at all

Figure 7: Relevance of automotive/electronics courses

New entries ability to integrate

$14.29 \%$

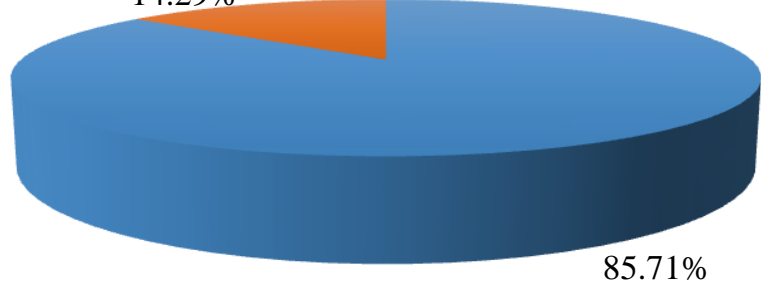

To a great extent $\quad$ To a lesser degree Not at all

Figure 8: New entries ability to integrate 


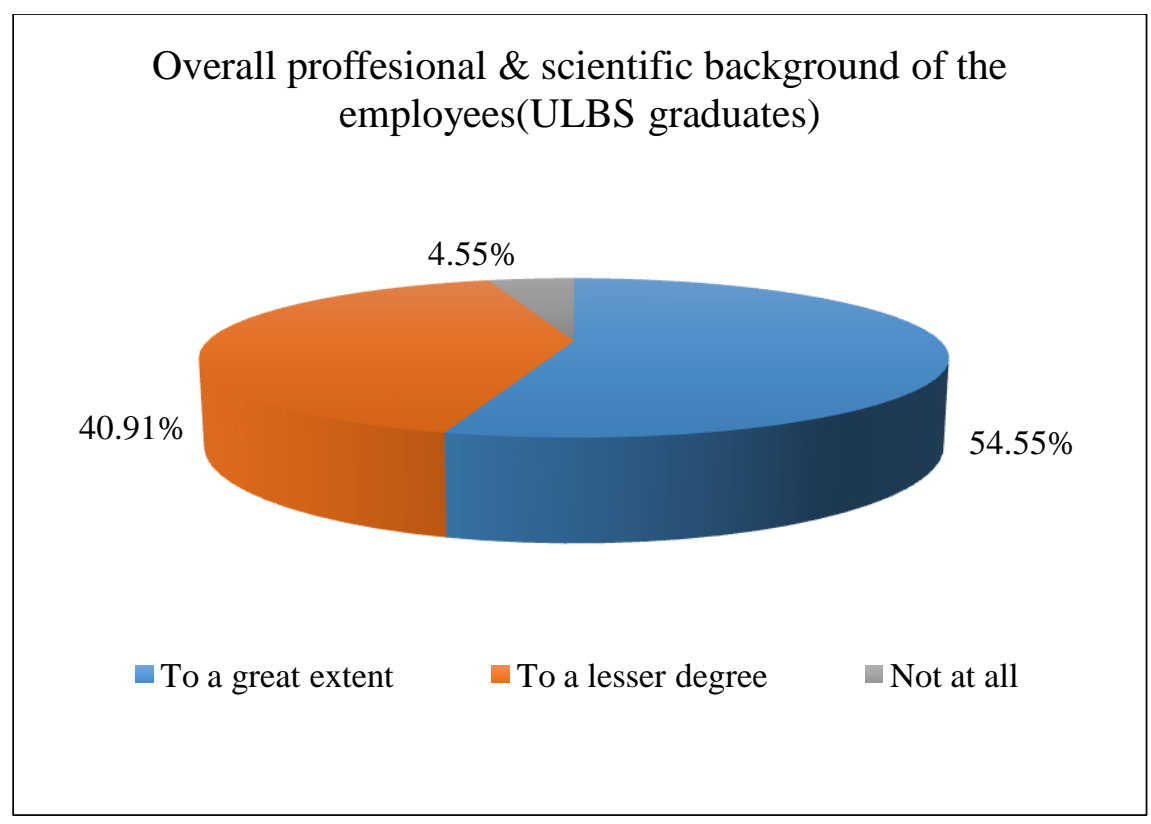

Figure 9: Overall professional and scientific background of the employees (ULBS graduates)

Company aproach towards lifelong learning

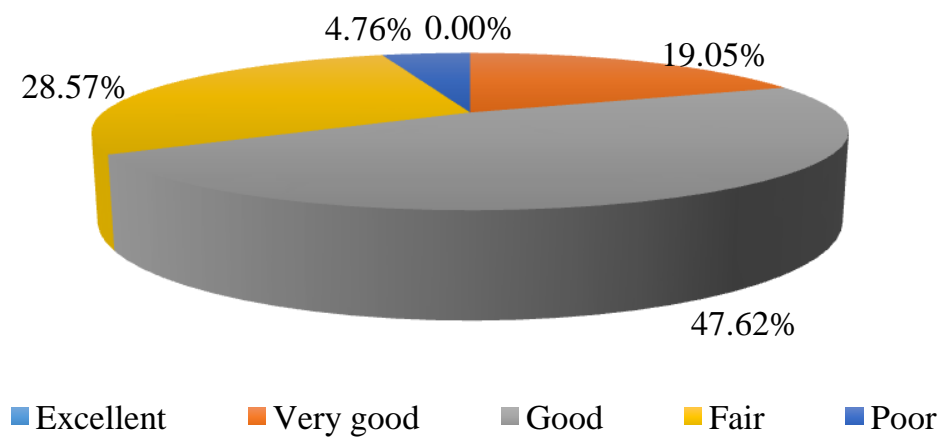

Figure 10: Company approach towards lifelong learning 


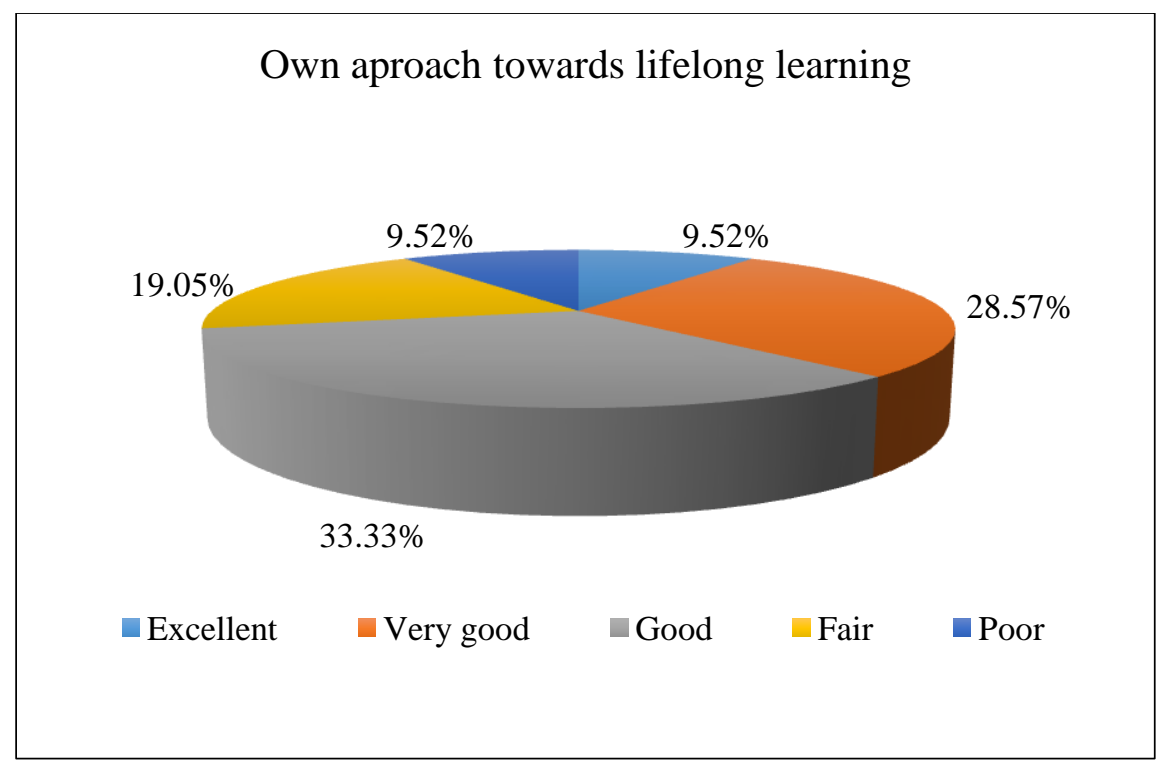

Figure 11: Own approach towards lifelong learning

\section{KEY FINDINGS AND RECOMMENDATIONS}

European Commission 2012 Communication on Rethinking Education points out that "European education and training systems continue to fall short in providing the right skills for employability, and are not working adequately with business or employers to bring the learning experience closer to the reality of the working environment." (European Commission, 2012)

The survey results show that the employers` perspective endorses the graduates` view regarding the gap between theoretical knowledge and work-related assignments, pointing out to the fact that their ability to apply theoretical knowledge does not fully meet the expectations of their team leaders. Mention should be made though that practical experience made a relevant difference in the case of former university graduates who benefited from the Conti internship program, and later became new entries to the company. Internship has complex, long-term and multiple benefits for both employers and employees as it proves to be an efficient tool in facilitating a smooth integration of new entries to their assigned team and tasks.

Furthermore, in their capacity as company representatives, team leaders strongly encourage and support lifelong learning and self-study in addition to technical and soft skills trainings provided by the company to all employees; besides, employers place a great emphasis on verbal and communication skills and recommend that such transversal competencies need to be improved by university graduates. 
Effective communication has come to be considered by employers as a top-ranking criterion in the recruitment process. „The main aspects that employers are concerned about regarding a university graduate have little connection with his or her academic studies. In a hierarchy of ,things'employers look for in a graduate, the first four positions are poorly connected with the academic characteristics: the graduate`s ability to work in a team, to organize his or her work, his or her punctuality, morality and communication skills - with peers, superiors, customers, etc." (ARACIS, 2009) Not only is communication a key competence for employability but it is also an essential characteristic of an ,effective teacher" as mentioned in the ARACIS Report on The State of Quality in Romanian Higher Education - Quality Barometer 2010: "In the students' opinion, communication and dialogue with students, professional qualities and the ability to explain represent, in this order, the basic qualities of a 'good teacher'. Thus, the pedagogical abilities are emphasized, namely the trainer abilities (the capacity to communicate and explain), and the abilities of a good professional in the field, only come next." (ARACIS, 2010)

The graduates` perspective also emphasizes the increasing need for improving foreign language skills in addition to a selection of the following courses that have proved relevant in the working context: communication, cultural management, translation, marketing, accounting, economics, human resources, business English. The questionnaire results identified and highlighted a selection of courses or competencies that would have been helpful in fulfilling the professional tasks assigned, such as: practical courses, foreign languages for specific purposes, logistics, project management, time management, problem solving, strategic planning, leadership, presentation skills, ethics and deontology, communication and negotiation.

To conclude, it is worth mentioning that employability is a combination of three major factors: "personal (personality, network, social background, special talent, etc), acquired in education (knowledge, know-how, etc) and external (labour market)." Hence, employability is a complex concept and it refers to "the ability to be employed, which requires some knowledge (know), skills (know how) and attitudes (how). A particular combination of these three types of factors makes a successful professional." Furthermore, "employability can be defined from the point of view of the individual (professional, job seeker), from the point of view of higher education institutions and from the point of view of employers." (EURASHE, 2013)

\section{REFERENCES:}

Tibor Navracsics, (2015)"Reinforcing the knowledge triangle to boost economic growth: How the EU is bringing together education, science and business", speech 24 March 2015; retrieved 2 May 2015 from http://ec.europa.eu/commission/20142019/navracsics/announcements/reinforcing-knowledge-triangle-boost-economic-growthhow-eu-bringing-together-education-science-and_en

2013 Asia-Pacific Education Research Institutes Network (ERI-Net) Regional Study on "Transversal Competencies in Education Policy \& Practice" (2015) published by 
UNESCO, ISBN: 978-92-9223-509-3 (electronic version), p. 3, retrieved 18 May 2015 from http://unesdoc.unesco.org/images/0023/002319/231907E.pdf

"These competencies encompass a range of non-traditional ideas, including: innovative thinking, creativity, adaptability, respect, global awareness and communication."

European Commission 2012 Communication on Rethinking Education, p. 2, retrieved 20 May 2015 from https://ec.europa.eu/digital-agenda/en/news/communication-rethinkingeducation

EU Practical Guide Connecting Universities to Regional Growth (September 2011) prepared by Professor John Goddard commissioned by DG Regional Policy (European Commission), pp. 3, 10-11

Legea 1/2011 Legea Educatiei Nationale - Legea Invatamantului publicata in Monitorul Oficial 18/2011 din 10.01.2011; art. 2(1) and art. 2(2)

Recommendation 2006/962/EC of the European Parliament and of the Council of 18 December 2006 on key competences for lifelong learning [Official Journal L 394 of 30.12.2006]

Note: the eight key competences are: communication in the mother tongue, communication in foreign languages, mathematical competence and basic competences in science and technology, digital competence, learning to learn, social and civic competences, sense of initiative and entrepreneurship, cultural awareness and expression

The Bologna Process 2020 - The European Higher Education Area in the new decade: "Communique on the Conference of European Ministers Responsible for Higher Education, Leuven and Louvain-la-Neuve, 28-29 April 2009

Note: here are the priorities for the Bologna Process 2020: providing equal opportunities to quality education, increasing participation in lifelong learning, promoting employability, developing student-centred learning outcomes and teaching missions, intertwining education, research and innovation, opening higher education institutions to the international fora, increasing opportunities for and quality of mobility, improving data collection, developing multidimensional transparency tools, guaranteeing funding

Daniel Smihula, Long Waves of Technological Changes (Studia Politica Slovaca), Issue 2, pp. 50-68, 2011

Note: this is a follow up of the author's previous article "The Waves of the Technological Innovations of the Modern Age and the Present Crisis" (2009). Based on the Kondratiev wave theory (long-economic cycle; including three phases: expansion, stagnation, recession) he developed a new approach modern technological waves: financial-agricultural revolution (1600-1780), industrial revolution (1780-1880), technical (1880-1940), scientific-technical revolution (1940-1985), information

ARACIS Report on Statistical Distribution, interpretations and options on The State of Quality in Romanian Higher Education - Quality Barometer 2009, p.14

ARACIS Report on The State of Quality in Romanian Higher Education - Quality Barometer 2010, p.16

EURASHE Initial Study on Employability Among Professional Higher Education Graduates in Europe, Study undertaken on the initiative of EURASHE`s Working Group 6 on Employability and Lifelong Learning, project funded with support from the European Union (2014), pp. 1-2 